\title{
Polycystic ovary syndrome. Revised diagnostic criteria and long-term health consequences
}

\author{
Eleni Kousta, George Tolis, Stephen Franks
}

Ippokration Hospital, Athens, Greece (G.T.), Institute of Reproductive \& Developmental Biology Imperial College London, Hammersmith Hospital, London U.K. (S.F.)

\begin{abstract}
The diagnostic criteria for polycystic ovary syndrome (PCOS) have recently been revised. The polycystic ovarian morphology has been introduced as part of the criteria and an international consensus has been achieved providing the basis for future research and collaboration. It is now accepted that polycystic ovary syndrome has important long-term health implications, including metabolic disorders and increased risk factors for cardiovascular disease. The overall risk of developing type 2 diabetes among women with PCOS was found to be increased 3-7 times. Women with PCOS have increased levels of cardiovascular risk factors: insulin resistance, obesity, dyslipidaemia, hypertension and markers of abnormal vascular function. However, the level of risk for cardiovascular disease remains uncertain. The limited epidemiological data available to date have shown no increase in cardiovascular events although the incidence of cerebrovascular events was increased. The evidence for an increased risk for endometrial carcinoma among women with PCOS is limited. Long-term epidemiological studies of women with well defined PCOS are needed in order to assess the risk of long-term health consequences, to identify the subgroups among PCOS women who need to be targeted and to determine the timing and nature of measures for intervention and prevention.
\end{abstract}

Key words: Diagnostic criteria, Long-term health consequences, Polycystic ovary syndrome

\section{INTRODUCTION}

Polycystic ovary syndrome (PCOS) is the most common endocrine disorder affecting women of reproductive age, its prevalence varying according to the definition used and the reference population ${ }^{1-4}$. Although first described almost 70 years ago ${ }^{5}$, there

Address correspondence and requests for reprints to:

Dr Eleni Kousta, 6 S. Arvanitaki Str., Corfu 49100, Greece,

Tel: +3026610 80561, Fax: +302661080562,

e-mail:1kousta@otenet.gr

Received 28-03-05, Revised 15-05-05, Accepted 20-06-05 has been no universal agreement about its definition. The most widely accepted definition has been the association of hyperandrogenism with chronic anovulation without specific underlying diseases of the adrenal or pituitary glands ${ }^{6}$. The introduction of modern, high-resolution diagnostic ultrasonography resulted in a morphologically based diagnosis of the syndrome ${ }^{1}$. However, polycystic ovarian morphology based on ultrasound scan was thought to be consistent with the syndrome but not essential for its diagnosis ${ }^{7}$. Recently the European Society for Human Reproduction and Embryology and the 
American Society for Reproductive Medicine (ESHRE/ASRM) formulated a new consensus regarding the definition of $\mathrm{PCOS}^{8}$. It is thus now defined as the presence of any two of the following three criteria: (i) polycystic ovaries on ultrasound scan; (ii) oligo-and/or anovulation; and (iii) clinical or biochemical evidence of hyperandrogenism, provided other aetiologies (congenital adrenal hyperplasia, androgen-secreting tumours, Cushing's syndrome) have been excluded. Furthermore, the ultrasound diagnostic criteria for PCO morphology have been redefined as the presence of 12 or more follicles in each ovary, measuring 2-9 $\mathrm{mm}$ in diameter, and/or increased ovarian volume $(>10 \mathrm{ml})^{8}$ (Figure 1). It was noted that if only one ovary matches this definition, it is sufficient to define PCO and that this definition does not apply to women on an oral contraceptive. The revised definition for PCOS provides an international framework for the assessment of PCOS and for future research and collaboration.

The clinical and biochemical features of the syndrome are heterogeneous and the combination and degree of expression of these features vary between individuals. In the last few years it has become clear that polycystic ovary syndrome is not simply a combination of hyperandrogenaemia and anovulation but has important long-term health implications ${ }^{1,7,8}$. Although disagreement about diagnostic criteria has

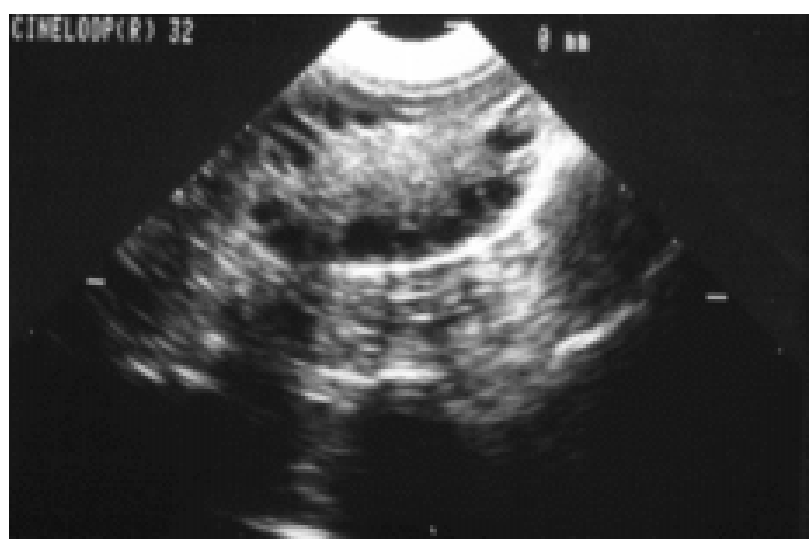

Figure 1. Polycystic ovarian morphology on the untrasound scan. The presence of 12 or more follicles in each ovary measuring 2$9 \mathrm{~mm}$ in diameter, and/or increased ovarian volume $(>10 \mathrm{ml})$ are the revised ultrasound criteria to define the polycystic ovarian morphology. up to now rendered comparison of epidemiological studies of long-term health risks difficult to achieve, it is now well accepted that PCOS is associated with metabolic disorders (hyperinsulinaemia and insulin resistance, impaired pancreatic $\beta$-cell function and increased risk of type 2 diabetes, obesity, hyperlipidaemia) and increased risk factors for cardiovascular disease. In addition, chronic anovulation in women with PCOS is thought to carry an increased risk of endometrial cancer ${ }^{8}$ (Table 1).

Diagnostic criteria for the metabolic syndrome among women with PCOS have recently been implemented. The definition requires 3 out of the following 5 criteria: central obesity, hypertriglyceridaemia, low HDL-C, increased blood pressure and hyperglycaemia ${ }^{8}$. These metabolic abnormalities, clustered together, are related to insulin resistance and are important as risk factors for cardiovascular disease and type 2 diabetes among women with PCOS.

In this mini-review, the long-term health consequences for PCOS are also discussed. In order to assess the impact of each individual factor in longterm health, risk factors-metabolic and cardiovascular-are treated separately.

\section{HYPERINSULINAEMIA AND INSULIN RESISTANCE}

Insulin resistance is common in the general, normoglycaemic population and varies according to body mass index (BMI) from 10\% among lean subjects to $26 \%$ or higher among obese subjects. Hypersecretion of insulin is more prevalent than insulin resistance in the obese population as a whole

Table 1. Long-term health implications of PCOS

Metabolic consequences:
- Hyperinsulinaemia and insulin resistance
- Impaired pancreatic $\beta$-cell function and increased risk of
$\quad$ type 2 diabetes
- Obesity
- Hyperlipidaemia
General consequenses:
- Increased cardiovascular risk factors
- Endometrial cancer


$(38 \%)^{9}$. Although insulin resistance is not a disease, its presence in both obese and nonobese subjects is associated with increased risk of cardiovascular morbidity and mortality and type 2 diabetes ${ }^{10}$.

There are several reports assessing insulin action among women with PCOS suggesting that women with PCOS have a greater frequency and degree of both hyperinsulinaemia and insulin resistance than age and weight matched controls ${ }^{7,11-15}$. Insulin resistance is independent of the effect of obesity; both lean and obese women with PCOS were found to be hyperinsulinaemic and insulin resistant compared to weight matched control subjects, but insulin resistance is more pronounced among obese women with $\operatorname{PCOS}^{7,14,16,17}$. Insulin resistance among PCOS women was associated with upper body fat distribution ${ }^{18}$, while weight reduction in obese PCOS women, especially reduction in abdominal adiposity, resulted in normalisation of insulin sensitivity, suggesting that body fat distribution is an important determinant of insulin resistance in $\mathrm{PCOS}^{19}$.

Interestingly, insulin resistance is not a feature of all women with PCOS. There are significant differences in insulin sensitivity between ovulatory and anovulatory women with PCOS. Anovulatory women with PCOS display insulin resistance whereas those with a regular menstrual cycle (but who present with symptoms of hyperandrogenism) do not demonstrate insulin resistance ${ }^{20,21}$. These observations suggest that there is a strong association between menstrual irregularity and insulin resistance among women with PCOS. Hyperinsulinaemia itself may contribute to the mechanism of anovulation and the expression of $\mathrm{PCOS}^{22}$. There is no resistance to the steroidogenic action of insulin in the ovaries, although evidence has recently emerged of a selective impairment of insulin-mediated glucose metabolism in the ovary ${ }^{23}$. The ovary is therefore exposed and responsive (at least in terms of steroid biosynthesis) to the high circulating levels of insulin. Insulin acts synergistically with LH to stimulate steroidogenesis and to induce premature arrest of the follicle development ${ }^{24}$.

Insulin resistance in PCOS has been associated with increased androgen levels, particularly free testosterone (by some but not all authors) $)^{7,19,25}$. Large doses of testosterone given to healthy female transsexuals can induce insulin resistance ${ }^{26}$. However, the interaction between hyperandrogenaemia and the precise aetiology of insulin resistance remain unresolved. Hirsute women with PCOS and hyperandrogenaemia who have regular menstrual cycles present fasting serum insulin concentrations and after-glucose stimulation that are indistinguishable from those in weight matched control subjects and present insulin sensitivity similar to control subjects ${ }^{14,21}$. Hyperandrogenaemia does not seem to cause insulin resistance; on the contrary, insulin may affect the expression of androgen by suppressing SHBG and augmenting androgen response to $\mathrm{LH}^{7}$. These observations suggest that hyperandrogenaemia is not a major determinant of insulin sensitivity in PCOS.

The cause of hyperinsulinaemia among women with PCOS also remains unknown. It may be related to increased insulin receptor serine phosphorylation, which decreases its protein tyrosine kinase activity and leads to a post-binding defect in insulin action and/or abnormal insulin secretion ${ }^{27,19}$. It may be that metabolic abnormalities in PCOS start very early in life, during the prenatal or prepubertal period, and an early exposure to androgens during development may affect body fat distribution and insulin action ${ }^{22,28}$.

The clinical implication of these observations is that women with PCOS are likely to have insulin resistance and/or hyperinsulinaemia, particularly when they are anovulatory and obese with central fat distribution. Given that insulin resistance is an independent risk factor for metabolic abnormalities, the presence of insulin resistance among PCOS women suggests future risk of cardiovascular disease and type 2 diabetes. Furthermore, using a cardiovascular risk score, insulin resistance in PCOS was found to be an important determinant of cardiovascular risk among women with PCOS independently of obesity ${ }^{16}$.

\section{IMPAIRED PANCREATIC B-CELL FUNCTION AND INCREASED RISK OF TYPE 2 DIABETES}

Even though the majority of women with PCOS have hyperinsulinaemia and insulin resistance and display increased insulin responses to a glucose load, 
studies that carefully assessed $\beta$-cell function demonstrate defects in insulin secretion in addition to insulin resistance ${ }^{29-31}$. Insulin secretory responses to mixed meals in insulin resistant women with PCOS are reduced relative to basal insulin secretion, an abnormality characteristic of type 2 diabetes ${ }^{29}$. Given that when insulin resistance occurs, the $\beta$-cell compensates by increasing the secretion of insulin, it is essential to take into account the degree of insulin sensitivity when assessing $\beta$-cell function. By using the intravenous glucose tolerance test (IVGTT), both lean and obese women with PCOS had $\beta$-cell dysfunction in addition to insulin resistance $^{31}$. The IVGTT has the advantage of estimating the disposition index (insulin sensitivity $\mathrm{x}$ acute insulin response to glucose), which allows $\beta$-cell function to be interpreted in the light of prevailing insulin resistance and the detection of subtle defects in $\beta$-cell function ${ }^{32}$. Defects in $\beta$-cell function are more evident among PCOS women who have $1^{\text {st }}$ degree relatives of type 2 diabetes as demonstrated by reduced insulin secretory responses either to bolus (IVGTT) or graded infusions of intravenous glucose and by impairment in the ability to entrain endogenous insulin secretion with glucose ${ }^{30}$. These observations suggest that women with PCOS, even when normoglycaemic, may demonstrate impaired $\beta$-cell function on detailed testing. This may be an early metabolic defect contributing to the development of type 2 diabetes later in life. Similar early metabolic changes have also been reported in other groups at high risk for future development of type 2 diabetes, such as normoglycaemic relatives of subjects with type 2 diabetes and/or women with a history of gestational diabetes ${ }^{33,34}$. Furthermore, recent data suggest that decreased glucose metabolism is present among women with PCOS even when insulin sensitivity and $\beta$-cell function are preserved, which may constitute an early feature of disturbed carbohydrate metabolism ${ }^{35}$.

The prevalence of type 2 diabetes has been reported as $3-4 \%$ in the general population, increasing up to $10-18 \%$ in old age ${ }^{36,37}$. Several groups have assessed glucose tolerance among PCOS women and the overall risk of developing type 2 diabetes was found to be increased 3-7 times ${ }^{13,38-41}$. The figures for prevalence rates of glucose intolerance among wom- en with PCOS are much higher than expected compared with reference populations of women of similar age: $31-35 \%$ had IGT and 7.5-10\% had type 2 diabetes ${ }^{36,39,40}$. Although obesity and age substantially increase the risk, IGT and diabetes are frequent even among non-obese PCOS women $(10 \%$ and $1.5 \%$, respectively $)^{40}$. Apart from obesity and age, waist $/$ hip ratio ${ }^{40}$, family history of type 2 diabetes ${ }^{39,40,42}$ and increased androgen concentrations ${ }^{39,42}$ were also associated with glucose intolerance. Oligomenorrhea was found to be a risk factor for the development of type $2 \mathrm{DM}$ and this risk was accentuated, though not totally explained, by obesity ${ }^{43}$.

The risk of glucose intolerance among PCOS women appears to be equally increased in mixed ethnicities of the US population and Asian PCOS groups $^{39,40,44}$. However, in a young Mediterranean population with PCOS the prevalence of glucose intolerance was lower than in previous reports $(2.5 \%$ type 2 diabetes and $16 \%$ impaired glucose tolerance), but there were no data for a control group of similar age and ethnicity ${ }^{42}$. In that study environmental factors explaining the lower prevalences of glucose intolerance, such as dietary habits, should be taken into account. In the same study lower birth weight and earlier age of menarche were associated with increased risk for glucose intolerance ${ }^{42}$.

Furthermore, the onset of glucose intolerance in PCOS women seems to occur at an early age, typically in the $3^{\text {rd }}-4^{\text {th }}$ decade of life, which is earlier than in the normal population ${ }^{36,37,39,40}$. Abnormalities in both insulin action and secretion and glucose intolerance have been observed even in adolescents with $\operatorname{PCOS}^{45,46}$ and in young girls with premature adrenarche (who may go on to develop PCOS in adolescence $)^{47}$. The prevalence of glucose intolerance has been reported to be as high as $30-40 \%$ among both lean and obese adolescents with $\operatorname{PCOS}^{48}$.

An association between gestational diabetes and PCOS has been observed. The prevalence of PCO morphology in women with previous GDM is significantly higher than in control women (41-52\% $)^{49-51}$, suggesting that women with PCO are at risk of developing gestational diabetes. Given that gestational diabetes is a forerunner of type 2 diabetes and the majority of women with gestational diabetes will 
develop type 2 diabetes in later life ${ }^{52}$, these observations reinforce the hypothesis of increased risk of diabetes in women with PCOS.

A significant percentage of $1^{\text {st }}$ degree relatives of the general population of women with PCOS have defects in insulin action and secretion or type 2 diabetes. In a recent study, a strong family history of type 2 diabetes was noted among parents of women with PCOS: $46 \%$ of the mothers and $58 \%$ of the fathers of women with PCOS had IGT or type 2 diabetes and female family members with normoglycaemia had insulin resistance ${ }^{53}$. Hyperinsulinaemia was found to be common among female and male $1^{\text {st }}$ degree relatives of women with $\mathrm{PCOS}^{54}$. Evidence for a familial correlation of $\beta$-cell dysfunction (strong sibling correlation for the acute insulin secretion and the disposition index), but no insulin resistance, was noted among families of women with $\mathrm{PCOS}^{55}$. In another study, $25 \%$ of the sisters of women with PCOS were affected (having menstrual irregularities and/or hyperandrogenaemia) and had increased insulin levels and decreased glucose/insulin ratios suggestive of insulin resistance, compared to control women ${ }^{56}$. These observations suggest that abnormalities of glucose regulation and type 2 diabetes are common among relatives of women with PCOS and that there is a strong association between the two diseases.

Women with PCOS have a greater chance of developing glucose intolerance at an earlier age than the general population. This risk is further emphasised by recent epidemiological observations that noted increased mortality from the complications of diabetes among women with PCOS ${ }^{57}$. Central obesity and family history of type 2 diabetes are parameters influencing the risk, as in the general population. Menstrual irregularity is probably an additional risk factor. Ethnicity does not appear to influence the risk, suggesting that PCOS is a more important risk factor.

\section{OBESITY}

Obesity is a known independent risk factor for the development of type 2 diabetes and cardiovascular disease. The prevalence of obesity is rising in societies which have adopted a westernised lifestyle and is today a major health issue ${ }^{58}$. In the general population, hyperinsulinaemia seems to be the main metabolic feature among normoglycaemic normotensive obese subjects, whereas insulin resistance is not as prevalent as previously thought ${ }^{9}$. Most importantly, cardiovascular morbidity and mortality are increased in obese women independently of other risk factors ${ }^{59}$.

The association between PCOS and obesity had been noted in early studies on PCOS. The prevalence of obesity among women with PCOS was observed to be as high as $41 \%$ when the diagnosis was based on histological features after wedge resec$\operatorname{tion}^{60}$. This prevalence varies from country to country, depending on the population studied and the criteria used to define PCOS. According to the UK studies, the prevalence of obesity among PCO women is $35-38 \%{ }^{61,62}$, whereas it is $36 \%$ in a black and white population in the $\mathrm{USA}^{2}, 10-38 \%$ in Mediterranean countries ${ }^{3,4}$ and as high as $63 \%$ in Australia where the diagnosis was based on stricter criteria ${ }^{63}$. Women with PCOS tend to have a central distribution of adiposity ${ }^{64,65}$. Obesity in adolescence and weight gain after adolescence were associated with PCOS symptoms among women of reproductive age $^{66}$.

Obesity in women with PCOS has not only longterm implications for the general health of the individual but additionally has important reproductive impacts (Table 2). Obese women with PCOS have a higher prevalence of menstrual disorders and infertility ${ }^{61}$, are more likely to be hirsute and have lower SHBG levels, leading to higher serum concentrations of free testosterone ${ }^{14,61}$, than lean women with PCOS. Obese women with PCOS are less likely to respond to induction of ovulation treatment ${ }^{67-69}$, require larger doses of gonadotropins to achieve

Table 2. Reproductive impact of obesity in PCOS

\footnotetext{
- Increased prevalence of menstrual disorders and hyperandrogenism

- Reduced response to ovulation induction, requirement for higher doses

- Increased prevalence of miscarriage

- Higher prevalence of pregnancy complications - including gestational diabetes
} 
ovulation and pregnancy ${ }^{67,68}$ and are more likely to miscarry $^{67,70,71}$. Furthermore, obesity in the overall population is associated with a higher prevalence of fetal abnormalities and more pregnancy complications including a higher risk for gestational diabetes $^{72}$.

Weight loss may, at least partially, reverse the biochemical abnormalities (including insulin resistance, hyperlipidaemia and dyslipidaemia) and improve reproductive function and hirsutism in obese women with $\mathrm{PCOS}^{19,73,74}$. Weight reduction in obese women with PCOS is encouraged before considering therapy to induce ovulation. Modifying additional lifestyle factors, including alcohol consumption, psychosocial stressors and smoking, are also crucial in the long-term outcome of $\mathrm{PCOS}^{75}$.

The factors, other than diet, that contribute to obesity among women with PCOS are unclear. An abnormality in energy expenditure in women with PCOS, notably in postprandial thermogenesis, has been implicated. Postprandial thermogenesis was significantly reduced in women with PCOS and there was a direct correlation of postprandial thermogenesis with insulin resistance ${ }^{15}$. It was calculated that if the difference in energy balance were maintained (as seems likely) over a year, women with PCOS would have an excess of $1.9 \mathrm{~kg}$ of fat. It may be that this represented an evolutionary advantage in periods of calorie restriction, but when calorie intake is excessive it may contribute to obesity.

In summary, a significant proportion of women with PCOS are affected by obesity. The cause of obesity among women with PCOS is unknown, but the presence of obesity in PCOS women has important long-term metabolic and reproductive consequences including increased risk for type 2 diabetes, cardiovascular disease, anovulation, infertility and miscarriage. Diet and lifestyle modification may improve reproductive function and fertility.

\section{HYPERLIPIDAEMIA}

It is well known that lipid abnormalities are associated with risk for cardiovascular disease. Highdensity lipoprotein (HDL-C) ${ }^{76,77}$, triglyceride levels and low-density lipoproteins (LDL-C) are strong independent predictors of cardiovascular death in women while total cholesterol levels have been shown to be poor predictors of cardiovascular mortality ${ }^{77}$.

Dyslipidaemia is common among women with PCOS. There are several studies reporting higher total cholesterol, LDL-C ${ }^{41,65,78,79}$, VLDL-cholesterol $^{80,81}$, triglycerides ${ }^{41,65,79,81}$ and lower HDL-cholesterol levels ${ }^{65,79,80,82}$ among women with PCOS compared with control women. Even after controlling for obesity, lipid abnormalities still persist between PCOS and control women ${ }^{16,65,79,83}$. In a large study of young white women with PCOS, increased LDL-C levels were the predominant lipid abnormality independent of obesity ${ }^{78}$. Furthermore, women with PCOS have raised concentrations of small LDL (LDL III) subfractions, considered to be more atherogenic ${ }^{84}$, and increased hepatic lipase activity compared to weight matched control women ${ }^{81}$. The difference in lipid profile is stronger at an earlier age and little difference is noted over the age of $40 \mathrm{yrs}$ between PCOS and control women, suggesting a higher risk for atherosclerosis at an earlier age $\mathrm{a}^{65,79}$. This may be due to an earlier onset of hormonal disturbances, obesity and intra-abdominal fat distribution among PCOS women or may reflect the LDL-C increase with age among controls.

Lipid abnormalities in PCOS appear to be related to central adiposity ${ }^{81}$ and hyperinsulinaemia ${ }^{16,81}$ in some but not in all studies ${ }^{78}$. Androgen levels were associated with triglyceride levels but not with other lipids $^{78}$, whereas others found no association between androgen levels and dyslipidaemia ${ }^{81}$. Interestingly, it was observed that women with hirsutism and regular cycles do not present dyslipidaemia compared to control women, whereas those with both hirsutism and oligomenorrhea had lower HDL-C and higher triglycerides ${ }^{85}$, suggesting an association between menstrual irregularity and dyslipidaemia.

Paradoxically, in a large study of young white women with PCOS, HDL-C levels were significantly higher even among obese subjects; however, this difference was not significant after adjusting for age, BMI, insulin and other variables ${ }^{78}$. It is unknown whether these increased HDL-C levels confer some protection against cardiovascular disease in young women with PCOS. 
The cause of dyslipidaemia among women with PCOS remains unknown. Dyslipidaemia is more pronounced among obese subjects but cannot totally be attributed to obesity. Dyslipidaemia seems to affect women with PCOS at a younger age, thus increasing the risk for atherosclerosis. Known risk factors of dyslipidaemia, such as central adiposity and insulin resistance, may play a significant role, while the role of androgens is still unclear. Women with menstrual irregularities are likely to be those exhibiting more pronounced dyslipidaemia.

\section{PREVALENCE OF OTHER CARDIOVASCULAR RISK FACTORS (TABLE 3)}

\section{Hypertension}

Data on blood pressure (BP) in women with PCOS are controversial. Blood pressure has been reported to be raised among PCOS women compared with control women, even after adjusting for $\mathrm{BMI}^{41,83}$ by some but not all investigators ${ }^{16}$. Obese women with PCOS were found to have increased systolic but not diastolic BP compared to weight matched control women, but there was no difference in BP levels among the non-obese group ${ }^{78}$. Women with oligomenorrhea and hirsutism had both systolic and diastolic BP raised, compared to control women ${ }^{85}$. Existing data however need to be interpreted with caution, while it is noteworthy that even small differences in BP may be of clinical relevance since at a group level a BP difference of $1.5-2 \mathrm{~mm}$ $\mathrm{Hg}$ could have a large impact on population cardiovascular risk ${ }^{86}$.

\section{Endothelial dysfunction, chronic inflammation and altered vascular function}

Endothelial dysfunction is an early event in the process of arterial lesion formation and precedes atherosclerosis. Assessment of endothelial function may be a useful prognostic tool for cardiovascular disease ${ }^{87}$. Endothelial function can be assessed directly by measuring peripheral circulation (flow mediated vasodilatation) or, indirectly, by the use of inflammatory markers.

An initial study on a small number of obese women with PCOS and age matched control women reported no difference in endothelial function (as-
Table 3. Cardiovascular risk factors in women with PCOS

- Insulin resistance

- Obesity

- Hyperlipidaemia

- Hypertension

- Endothelial dysfunction and chronic vascular inflammation

- Increased vascular thickness

sessed as endothelium-dependent and -independent vascular function by brachial artery ultrasound) between the two groups, despite the presence of insulin resistance and hyperandrogenism among PCOS subjects $^{88}$. The authors commented that their findings could be attributed to the protective effects of estrogen exposure and/or HDL cholesterol, which did not differ between the two groups. However, subsequent studies reported impaired endothelial function among women with PCOS ${ }^{89-91}$. These findings were present even among young, normotensive, non-obese and non-dyslipidaemic women with PCOS, as assessed by flow mediated dilatation on the branchial arteries ${ }^{90}$. Resistance to the vasodilating action of insulin was noted and endothelial dysfunction was associated with obesity, insulin resistance and androgen levels in women with $\mathrm{PCOS}^{89}$. In this study, leg blood flow responses to the intrafemoral artery were measured in response to infusions of the endothelium-dependent vasodilator methacholine chloride and to euglycemic hyperinsulinemia. Abnormal vascular compliance suggesting vascular stiffness (assessed by recording pulse wave velocity across the aorta and brachial artery) and functional defect in the vascular action of insulin (studied by wire myography, by measuring the concentration response curve to norepinephrine before and after incubation with insulin) was revealed in obese women with PCOS compared to weight matched control subjects ${ }^{92}$. These findings are consistent with early vascular changes associated with insulin resistance.

Endothelin-1 is a marker for abnormal vascular reactivity, which is postulated to contribute to the atherosclerotic process ${ }^{93}$. Insulin has a stimulating effect on endothelin-1 and it was hypothesised that interaction could play a significant role in the development of atherosclerotic lesions in hyperin- 
sulinemic conditions ${ }^{94}$. Endothelin-1 is elevated in patients with atherosclerosis ${ }^{93}$, diabetes and obesity ${ }^{95}$. Endothelin-1 was found to be raised in women with PCOS, independently of obesity ${ }^{90,96}$, suggesting an early vascular impairment.

Chronic inflammation results in endothelial dysfunction and facilitates the initiation of an atherosclerotic process. Several studies suggest that low grade inflammation, reflected by elevated C-reactive protein (CRP), can contribute to the development of arteriosclerosis ${ }^{97,98}$. CRP is considered not only an inflammatory marker of atherosclerosis but also a mediator of the disease because it contributes to the pathogenesis of lesion formation by interacting with the endothelium and therefore CRP can be seen as a measure of endothelial dysfunction $^{87}$. CRP can independently predict type 2 diabetes $^{99}$ and has been linked to insulin resistance ${ }^{100}$. However, the role of inflammation in the etiology of cardiovascular disease (CVD) and other metabolic diseases is still disputed and is not generally accepted $^{101-103}$. CRP concentrations were significantly increased in women with PCOS compared to BMI matched control women, and correlated positively with the degree of obesity and inversely with insulin sensitivity ${ }^{91,104}$, although not with total testosterone concentrations ${ }^{104}$. In another study, CRP levels were higher among women with oligomenorrhea and/or hirsutism than in control women, but after stratification by BMI the differences did not persist ${ }^{85}$.

\section{Premature atherosclerosis}

Greater carotid intima-media thickness, suggestive of an increased risk for atherosclerosis, was shown in a small number of women with PCOS over 40 years of age, though there was no significant difference in the prevalence of carotid plaque between women with PCOS and controls ${ }^{105}$. When the study was extended to a larger group of white women, the difference in mean carotid IMT between PCOS women and controls, after adjustment for age and BMI, was only noted in women $\geq 45$ years, but not in the younger group (aged 30-44 years) ${ }^{106}$. Central obesity was associated with greater extent of carotid IMT among PCOS. Furthermore, the overall group of PCOS women had an increased prevalence of carotid plaque compared to control women ${ }^{106}$.
Subsequent studies confirmed the increase in IMT among young PCOS women compared to age and BMI matched control subjects ${ }^{90,107}$.

Recently, obese premenopausal PCOS women (aged 30-45 years) were shown to have a greater prevalence and extent of coronary artery calcium, a marker for coronary atherosclerosis measured by electron beam computed tomography, than anticipated ${ }^{108}$. However, it may be that central obesity and dyslipidaemia, present in that group of women with PCOS, contributed to the increased risk for atherosclerosis ${ }^{108}$. Also, the presence of PCO (on ultrasound scan) was associated with more extensive coronary artery disease among a mixed population of pre- and post-menopausal women (all younger than 60 years, with a mean age of 54 and 52 years among women with normal and PCO ovaries, respectively) who had coronary angiography ${ }^{109}$.

These observations suggest that women with PCOS display altered endothelial function, low grade chronic vascular inflammation and increased vascular thickness. These abnormalities are indicative of the early stages of atherosclerosis and therefore suggest an increased risk of atherosclerosis at an earlier age than expected. It is not known whether the cause of these abnormalities can be attributed to PCOS per se or to the metabolic disturbances of the syndrome.

\section{CARDIOVASCULAR EVENTS}

It has been predicted, based on a risk factor model-taking into account risk factor variables and comparing them with a reference population-, that the risk of developing myocardial infarction is considerably increased (relative risk of 7.4) for women with PCOS compared to age matched control women ${ }^{110}$.

Although cardiovascular risk factors are increased among women with PCOS, increased prevalence of cardiovascular events has not been confirmed. In a large retrospective study of 786 women with PCOS in the UK, mortality and morbidity rates from cardiovascular disease were not higher than anticipated ${ }^{57}$. The diagnosis of PCOS was made on ovarian histopathology; the majority of these women had undergone wedge resection about 30 years 
Table 4. Assessment of endothelial function in women with PCOS- tests of peripheral circulation and inflammatory markers

\begin{tabular}{|c|c|c|c|c|}
\hline Authors & $\begin{array}{l}\text { Subjects } \\
\quad(\mathrm{n})\end{array}$ & $\begin{array}{l}\text { Age (years) } \\
\quad(\text { mean })\end{array}$ & Method & Findings \\
\hline $\begin{array}{l}\text { Mather et al } \\
\text { (JCEM) } \\
2000\end{array}$ & $\begin{array}{l}18 \text { obese PCOS } \\
19 \text { controls }\end{array}$ & 32 & $\begin{array}{l}\text { Assessment of endothelium dependent } \\
\text { and independent (response to } \\
\text { nitroglycerin) vascular reactivity } \\
\text { using brachial artery ultrasound }\end{array}$ & No difference between groups \\
\hline $\begin{array}{l}\text { Paradisi } \\
\text { et al } 2001\end{array}$ & $\begin{array}{l}12 \text { obese PCOS } \\
13 \text { obese } \\
\text { controls }\end{array}$ & $\begin{array}{l}\text { PCOS: } 29 \\
\text { controls: } 35\end{array}$ & $\begin{array}{l}\text { Assessment of endothelium dependent } \\
\text { vasodilation by measuring leg blood } \\
\text { flow responses to intrafemoral artery } \\
\text { infusions of methacholine chloride } \\
\text { and to euglycemic hyperinsulinaemia }\end{array}$ & $\begin{array}{l}\text { Approximately } 50 \% \text { reduction } \\
\text { in endothelium dependent } \\
\text { vasodilation and resistance to } \\
\text { the vasodilating action of insulin } \\
\text { among women with PCOS }\end{array}$ \\
\hline $\begin{array}{l}\text { Diamanti- } \\
\text { Kandarakis } \\
\text { et al } 2001\end{array}$ & $\begin{array}{l}43 \text { PCOS } \\
(23 \text { obese and } \\
20 \text { nonobese) } \\
17 \text { controls } \\
\text { ( } 7 \text { obese and } \\
10 \text { nonobese) }\end{array}$ & 23 & Measurement of endothelin-1 & $\begin{array}{l}\text { Significantly higher endothelin-1 } \\
\text { levels among both lean and obese } \\
\text { women with PCOS }\end{array}$ \\
\hline $\begin{array}{l}\text { Kelly } \\
\text { et al } 2001\end{array}$ & $\begin{array}{l}17 \text { PCOS (mean } \\
\left.\text { BMI } 31.5 \mathrm{~kg} / \mathrm{m}^{2}\right) \\
15 \text { controls }(\text { mean } \\
\left.\text { BMI } 30.3 \mathrm{~kg} / \mathrm{m}^{2}\right)\end{array}$ & $\begin{array}{c}\text { PCOS: } 26 \\
\text { controls: } 33\end{array}$ & Measurement of CRP levels & $\begin{array}{l}\text { Significantly higher CRP levels } \\
\text { among women with PCOS }\end{array}$ \\
\hline $\begin{array}{l}\text { Taponen } \\
\text { et al } 2004\end{array}$ & $\begin{array}{l}518 \text { cases with } \\
\text { oligomenorrhea/and/ } \\
\text { or hirsutism (mean } \\
\left.\text { BMI } 25.1 \mathrm{~kg} / \mathrm{m}^{2}\right) \\
1036 \text { controls (mean } \\
\left.\text { BMI } 24.2 \mathrm{~kg} / \mathrm{m}^{2}\right)\end{array}$ & 31 & Measurement of CRP levels & $\begin{array}{l}\text { Significantly higher CPR levels } \\
\text { among cases, after stratification } \\
\text { for BMI differences are lost }\end{array}$ \\
\hline $\begin{array}{l}\text { Orio et al } \\
2004\end{array}$ & $\begin{array}{l}30 \text { PCOS } \\
30 \text { controls } \\
\text { All subjects had } \\
\text { a BMI between } \\
18 \text { and } 25\end{array}$ & 22 & $\begin{array}{l}\text { Assessment of endothelium } \\
\text { dependent vascular reactivity } \\
\text { using brachial artery ultrasound. } \\
\text { Measurement of endothelin-1 }\end{array}$ & $\begin{array}{l}\text { Significantly decreased flow } \\
\text { mediated-dilation and significantly } \\
\text { higher endothelin-1 levels among } \\
\text { women with PCOS. }\end{array}$ \\
\hline $\begin{array}{l}\text { Tarkun } \\
\text { et al } 2004\end{array}$ & $\begin{array}{l}37 \text { PCOS } \\
(\text { mean BMI } \\
\left.23.8 \mathrm{~kg} / \mathrm{m}^{2}\right) \\
25 \text { controls } \\
(\text { mean BMI } \\
\left.22.9 \mathrm{~kg} / \mathrm{m}^{2}\right)\end{array}$ & $\begin{array}{l}\text { PCOS: } 23 \\
\text { controls: } 24\end{array}$ & $\begin{array}{l}\text { Assessment of endothelium dependent } \\
\text { and independent (response to } \\
\text { nitroglycerin) vascular reactivity } \\
\text { using brachial artery ultrasound. } \\
\text { Measurement of CRP levels }\end{array}$ & $\begin{array}{l}\text { Significantly decreased flow and } \\
\text { nitroglycerin mediated- } \\
\text { (endothelium dependent } \\
\text { and independent) dilation } \\
\text { and significantly higher CRP } \\
\text { levels among women with PCOS }\end{array}$ \\
\hline
\end{tabular}

before the follow-up study. Observed death rates were compared with expected deaths using standardised mortality rates. There was an increased number of deaths where type 2 diabetes was a complicating factor ${ }^{57}$. A more detailed subsequent study by the same research group showed that cardiovascular morbidity and mortality in women with PCOS were similar to those in the general population ${ }^{41}$.
Although the history of coronary heart disease was not more common among women with PCOS, the history of cerebrovascular disease was increased. Women with PCOS had higher levels of several cardiovascular and metabolic risk factors such as diabetes, hypertension, hypercholesterolaemia, hypertriglyceridaemia and increased waist/hip ratio. After adjusting for BMI the differences for diabetes, 
hypertension and hypercholesterolaemia remained significant. An increased prevalence of family history for type 2 diabetes was also noted ${ }^{41}$.

Given the increased prevalence of cardiovascular and metabolic risk factors among women with PCOS, it is perhaps surprising that there was no significant increase in the prevalence of cardiovascular events. Subjects studied were middle-aged at the time of observation (the mean age in the Wild et al study was 57 years), and the prevalence of cardiovascular events in both study and reference groups was low. It may be that, as the cohort ages, there will be a divergence between PCO and control groups in the incidence of coronary heart disease. Moreover, these subjects were recruited mostly through their recorded treatment by ovarian wedge resection. This treatment is known to have shortterm benefits for PCOS but, although unlikely, longterm benefits in terms of cardiovascular health in those women cannot be excluded. On the other hand, those women with PCOS who underwent wedge resection are likely to be those with the more severe symptoms of the syndrome. Nevertheless, irrespective of any effect of surgical intervention, the presence of a protective factor against cardiovascular disease related to PCOS cannot be excluded. Further long-term epidemiological studies are needed before definite conclusions can be drawn. In the meantime, it seems sensible to counsel patients "at risk" (i.e. particularly obese, anovulatory women with PCOS) about possible long-term risk of cardiovascular disease and to implement dietary and lifestyle changes where appropriate ${ }^{8,111}$.

\section{ENDOMETRIAL CANCER}

An association between PCOS and endometrial carcinoma was first suggested in 1949, 14 years after the original description of the syndrome ${ }^{112}$. Women with PCOS have been thought to be at increased risk for endometrial cancer through chronic anovulation and unopposed estrogen exposure of the endometrium. However, the evidence for such an association in epidemiological studies is incomplete and contradictory ${ }^{113}$. Many studies providing evidence of an increased risk of endometrial cancer in women with PCOS do not provide an estimate of the relative risk compared with the general population, or when the observations were compared to control women the numbers of the subjects were small $^{113}$.

The risk of developing endometrial cancer has been shown to be influenced by a number of factors including long-term exposure to unopposed estrogens, obesity, nulliparity and infertility ${ }^{114}$. Women with anovulatory infertility were found to be at risk of developing endometrial hyperplasia and, in some cases, this will be atypical and therefore premalignant ${ }^{114-116}$. In one of these studies it was noted that the risk for endometrial carcinoma was increased only among the obese subgroup of anovulatory wom$\mathrm{en}^{116}$. Although most, but not all, of the women with chronic anovulation have PCOS, and additionally not all women with PCOS have anovulation, the risk for endometrial carcinoma based on anovulatory subjects cannot be applied to all women with PCOS.

Obese women in the general population are at increased risk for endometrial cancer compared to normal weight women, and hypertension and relative hyperglycaemia were found to be significant markers of risk ${ }^{117,118}$. Women with types 1 and 2 diabetes mellitus have also been shown to be at increased risk for endometrial cancer ${ }^{118}$. It needs to be borne in mind that the apparent association between PCOS and endometrial carcinoma may be related to metabolic abnormalities arising as a result of the syndrome. In a retrospective study of 345 women with PCOS, analysing the various causes of morbidity and mortality, a significant risk of endometrial carcinoma was observed among PCOS women (OR 5.3), but obesity could be a confounding factor ${ }^{41}$.

There are no prospective studies demonstrating increased risk for endometrial carcinoma among women with PCOS. PCOS is associated with risk factors for endometrial cancer, but it has not yet been clarified whether the incidence or mortality from endometrial cancer among PCOS is increased. It is likely that obese women with PCOS and oligomenorrhea or amenorrhea are at greater risk. Due to limited data, universal screening or preventive strategies for these women cannot be applied at present but in order to prevent endometrial hyperplasia it 
has been considered important to shed the endometrium by inducing withdrawal bleed at least every 3 months among women with PCOS who have oligomenorrhea or amenorrhea ${ }^{119}$.

\section{SUMMARY}

The overall risk of the development of type 2 diabetes was found to be increased 3-7 times among women with PCOS. Women with PCOS have several risk factors for developing type 2 diabetes including central obesity, abnormalities in insulin action and secretion and a family history of type $2 \mathrm{di}-$ abetes. Menstrual irregularity may be an additional risk factor. Furthermore, mortality from the complications of diabetes is increased among women with PCOS.

Women with PCOS have increased levels of cardiovascular risk factors: insulin resistance, obesity, dyslipidaemia, hypertension and markers of abnormal vascular function. This adverse cardiovascular risk profile may start at an early age and may lead to premature atherosclerosis. However, the level of risk of cardiovascular disease is uncertain. The limited epidemiological data available to date have shown no increase in cardiovascular events, although the incidence of cerebrovascular events was increased.

Women with PCOS are predisposed to obesity. Obesity is an important independent risk factor for cardiovascular disease and type 2 diabetes. The presence of obesity in PCOS women has not only longterm metabolic health consequences but also important reproductive consequences including anovulation, infertility and miscarriage. Diet and lifestyle modification may improve reproductive function and fertility.

Women with PCOS have been thought to have increased risk for endometrial carcinoma, through anovulation and increased exposure to unopposed estrogen; however, epidemiological data to support this hypothesis is limited. Among the overall group of women with PCOS, those who have the greater prevalence of cardiovascular risk factors and are at higher risk for type 2 diabetes and endometrial carcinoma are those who are anovulatory and obese.
The new consensus regarding the definition of PCOS provides an international framework for the clinical assessment of PCOS and for future research and collaboration. Importantly, there are as yet no large, long-term studies of women with well defined PCOS that will allow clear assessment of the risk of disease in later life. Such epidemiological studies are needed to assess the risk of long-term health consequences, to identify the subgroups among PCOS women which need to be targeted and to determine the timing and nature of measures for intervention and prevention.

\section{REFERENCES}

1. Franks S, 1995 Polycystic ovary syndrome. N Engl J Med 333: 853-861.

2. Knochenhauer ES, Key TJ, Kahsar-Miller M, Waggoner W, Boots LR, Azziz R, 1998 Prevalence of the polycystic ovary syndrome in unselected black and white women of the southeastern United States: a prospective study. J Clin Endocrinol Metab 83: 3078-3082.

3. Diamanti-Kandarakis E, Kouli CR, Bergiele AT, et al, 1999 A survey of the polycystic ovary syndrome in the Greek island of Lesbos: hormonal and metabolic profile. J Clin Endocrinol Metab 84: 4006-4011.

4. Asuncion M, Calvo RM, San Millan JL, Sancho J, Avila S, Escobar-Morreale HF, 2000 A prospective study of the prevalence of the polycystic ovary syndrome in unselected Caucasian women from Spain. J Clin Endocrinol Metab 85: 2434-2438.

5. Stein IF, Leventhal ML, 1935 Amenorrhea associated with bilateral polycystic ovaries. Am J Obstet Gynecol 29: 181-191.

6. Zawadzki JK, Dunaif A 1992 Diagnostic criteria for polycystic ovary syndrome: towards a rational approach In: Dunaif A, Givens JR, Haseltine FR, Merriam GR (eds) Polycystic ovary syndrome, Oxford, England: Blackwell Scientific; pp, 377-384.

7. Dunaif A, 1997 Insulin resistance and the polycystic ovary syndrome: mechanism of action and implications for pathogenesis. Endocr Rev 18: 774-800.

8. The Rotterdam ESHRE/ASRM-Sponsored PCOS consensus workshop group, 2004 Revised 2003 consensus on diagnostic criteria and long-term health risks related to polycystic ovary syndrome (PCOS). Hum Reprod 19: 41-47.

9. Ferrannini E, Natali A, Bell P, Cavallo-Perin P, Lalic N, Mingrone G, 1997 Insulin resistance and hypersecretion in obesity. European Group for the Study of Insulin Resistance (EGIR). J Clin Invest 100: 11661173.

10. Reaven G, 2002 Metabolic syndrome: pathophysiolo- 
gy and implications for management of cardiovascular disease. Circulation 106: 286-288.

11. Burghen GA, Givens JR, Kitabchi AE, 1980 Correlation of hyperandrogenism with hyperinsulinism in polycystic ovarian disease. J Clin Endocrinol Metab 50: 113116.

12. Shoupe D, Kumar DD, Lobo RA, 1983 Insulin resistance in polycystic ovary syndrome. Am J Obstet Gynecol 147: 588-592.

13. Dunaif A, Graf M, Mandeli J, Laumas V, Dobrjansky A, 1987 Characterization of groups of hyperandrogenic women with acanthosis nigricans, impaired glucose tolerance, and/or hyperinsulinemia. J Clin Endocrinol Metab 65: 499-507.

14. Conway GS, Jacobs HS, Holly JM, Wass JA, 1990 Effects of luteinizing hormone, insulin, insulin-like growth factor-I and insulin-like growth factor small binding protein 1 in the polycystic ovary syndrome. Clin Endocrinol (Oxf) 33: 593-603.

15. Robinson S, Chan SP, Spacey S, Anyaoku V, Johnston DG, Franks S, 1992 Postprandial thermogenesis is reduced in polycystic ovary syndrome and is associated with increased insulin resistance. Clin Endocrinol (Oxf) 36: 537-543.

16. Mather KJ, Kwan F, Corenblum B, 2000 Hyperinsulinemia in polycystic ovary syndrome correlates with increased cardiovascular risk independent of obesity. Fertil Steril 73: 150-156.

17. Toprak S, Yonem A, Cakir B, et al, 2001 Insulin resistance in nonobese patients with polycystic ovary syndrome. Horm Res 55: 65-70.

18. Holte J, Bergh T, Berne C, Berglund L, Lithell H, 1994 Enhanced early insulin response to glucose in relation to insulin resistance in women with polycystic ovary syndrome and normal glucose tolerance. J Clin Endocrinol Metab 78: 1052-1058.

19. Holte J, Bergh T, Berne C, Wide L, Lithell H, 1995 Restored insulin sensitivity but persistently increased early insulin secretion after weight loss in obese women with polycystic ovary syndrome. J Clin Endocrinol Metab 80: 2586-2593.

20. Dunaif A, Segal KR, Futterweit W, Dobrjansky A, 1989 Profound peripheral insulin resistance, independent of obesity, in polycystic ovary syndrome. Diabetes 38 : 1165-1174.

21. Robinson S, Kiddy D, Gelding SV, et al, 1993 The relationship of insulin insensitivity to menstrual pattern in women with hyperandrogenism and polycystic ovaries. Clin Endocrinol 39: 351-355.

22. Abbott DH, Dumesic DA, Franks S, 2002 Developmental origin of polycystic ovary syndrome - a hypothesis. J Endocrinol 174: 1-5.

23. Rice S, Christoforidis N, Gadd C, et al, 2005 Impaired insulin-dependent glucose metabolism in granulosalutein cells from anovulatory women with polycystic ovaries. Hum Reprod 20:373-381.
24. Willis DS, Watson H, Mason HD, Galea R, Brincat M, Franks S, 1998 Premature response to luteinizing hormone of granulosa cells from anovulatory women with polycystic ovary syndrome: relevance to mechanism of anovulation. J Clin Endocrinol Metab 83: 39843991.

25. Toscano V, Bianchi P, Balducci R, et al, 1992 Lack of linear relationship between hyperinsulinaemia and hyperandrogenism. Clin Endocrinol 36: 197-202.

26. Polderman KH, Gooren LJ, Asscheman H, Bakker A, Heine RJ, 1994 Induction of insulin resistance by androgens and estrogens. J Clin Endocrinol Metab 79: 265-271.

27. Dunaif A, Xia J, Book CB, Schenker E, Tang Z, 1995 Excessive insulin receptor serine phosphorylation in cultured fibroblasts and in skeletal muscle. A potential mechanism for insulin resistance in the polycystic ovary syndrome. J Clin Invest 96: 801-810.

28. Eisner JR, Barnett MA, Dumesic DA, Abbott DH, 2002 Ovarian hyperandrogenism in adult female rhesus monkeys exposed to prenatal androgen excess. Fertil Steril 77: 167-172.

29. O’Meara NM, Blackman JD, Ehrmann DA, et al, 1993 Defects in beta-cell function in functional ovarian hyperandrogenism. Clin Endocrinol Metab 76: 1241-1247.

30. Ehrmann DA, Sturis J, Byrne MM, Karrison T, Rosenfield RL, Polonsky KS, 1995 Insulin secretory defects in polycystic ovary syndrome. Relationship to insulin sensitivity and family history of non-insulin-dependent diabetes mellitus. J Clin Invest 96: 520-527.

31. Dunaif A, Finegood DT, 1996 Beta-cell dysfunction independent of obesity and glucose intolerance in the polycystic ovary syndrome. J Clin Endocrinol Metab 81: 942-947.

32. Kahn SE, Prigeon RL, McCulloc DK, et al, 1993 Quantification of the relationship between insulin sensitivity and beta-cell function in human subjects. Evidence for a hyperbolic function. Diabetes 42: 1663-1672.

33. Fernandez-Castaner M, Biarnes J, Camps I, Ripolles J, Gomez N, Soler J, 1996 Beta-cell dysfunction in firstdegree relatives of patients with non-insulin-dependent diabetes mellitus. Diabet Med 13: 953-959.

34. Kousta E, Lawrence NJ, Godsland IF, et al, 2003 Insulin resistance and beta-cell dysfunction in normoglycaemic European women with a history of gestational diabetes. Clin Endocrinol 59: 289-297.

35. Gennarelli G, Rovei V, Novi RF, Holte J, Bongioanni F, Revelli A, Pacini G, Gavallo-Perin P, Massobrio M, 2005 Preserved insulin sensitivity and beta-cell activity, but decreased glucose effectiveness in normalweight women with the polycystic ovary syndrome. J Clin Endocrinol Metab 90: 3381-3386.

36. Harris MI, Hadden WC, Knowler WC, Bennett PH, 1987 Prevalence of diabetes and impaired glucose tolerance and plasma glucose levels in U.S. population aged 20-74 yr. Diabetes 36: 523-534. 
37. King H, Rewers M, 1993 Global estimates for prevalence of diabetes mellitus and impaired glucose tolerance in adults. WHO Ad Hoc Diabetes Reporting Group. Diabetes Care 16: 157-77.

38. Dahlgren E, Johansson S, Lindstedt G, et al, 1992 Women with polycystic ovary syndrome wedge resected in 1956 to 1965: a long-term follow-up focusing on natural history and circulating hormones. Fertil Steril 57: 505-513.

39. Ehrmann DA, Barnes RB, Rosenfield RL, Cavaghan MK, Imperial J, 1999 Prevalence of impaired glucose tolerance and diabetes in women with polycystic ovary syndrome. Diabetes Care 22: 141-146.

40. Legro RS, Kunselman AR, Dodson WC, Dunaif A, 1999 Prevalence and predictors of risk for type 2 diabetes mellitus and impaired glucose tolerance in polycystic ovary syndrome: a prospective, controlled study in 254 affected women. J Clin Endocrinol Metab 84: 165-169.

41. Wild S, Pierpoint T, McKeigue P, Jacobs H, 2000 Cardiovascular disease in women with polycystic ovary syndrome at long-term follow-up: a retrospective cohort study. Clin Endocrinol 52: 595-600.

42. Gambineri A, Pelusi C, Manicardi E, et al, 2004 Glucose intolerance in a large cohort of Mediterranean women with polycystic ovary syndrome: phenotype and associated factors. Diabetes 53: 2353-2358.

43. Solomon CG, Hu FB, Dunaif A, et al, 2001 Long or highly irregular menstrual cycles as a marker for risk of type 2 diabetes mellitus. JAMA 286: 2421-2426.

44. Weerakiet S, Srisombut C, Bunnag P, Sangtong S, Chuangsoongnoen N, Rojanasakul A, 2001 Prevalence of type 2 diabetes mellitus and impaired glucose tolerance in Asian women with polycystic ovary syndrome. Int J Gynaecol Obstet 75: 177-184.

45. Arslanian SA, Lewy VD, Danadian K, 2001 Glucose intolerance in obese adolescents with polycystic ovary syndrome: roles of insulin resistance and beta-cell dysfunction and risk of cardiovascular disease J Clin Endocrinol Metab 86: 66-71.

46. Lewy VD, Danadian K, Witchel SF, Arslanian S, 2001 Early metabolic abnormalities in adolescent girls with polycystic ovarian syndrome. J Pediatr 138: 38-44.

47. Ibanez L, Dimartino-Nardi J, Potau N, Saenger P, 2000 Premature adrenarche-normal variant or forerunner of adult disease? Endocr Rev 21: 671-696.

48. Palmert MR, Gordon CM, Kartashov AI, Legro RS, Emans SJ, Dunaif A, 2002 Screening for abnormal glucose tolerance in adolescents with polycystic ovary syndrome. J Clin Endocrinol Metab 87: 1017-1023.

49. Holte J, Gennarelli G, Wide L, Lithell H, Berne C, 1998 High prevalence of polycystic ovaries and associated clinical, endocrine, and metabolic features in women with previous gestational diabetes mellitus. J Clin Endocrinol Metab 83: 1143-1150.

50. Anttila L, Karjala K, Penttila A, Ruutiainen K, Ekblad
U, 1998 Polycystic ovaries in women with gestational diabetes. Obstet Gynecol 92: 13-16.

51. Kousta E, Cela E, Lawrence NJ, et al, 2000 The prevalence of polycystic ovaries in women with a history of gestational diabetes. Clin Endocrinol 53: 501-507.

52. O'Sullivan JB 1995 The interaction between pregnancy, diabetes and long-term maternal outcome In: Reece EA, Coustan DR (eds) Diabetes Mellitus in Pregnancy, New York, Churchill Livingstone; pp, 389-398.

53. Yildiz BO, Yarali H, Oguz H, Bayraktar M, 2003 Glucose intolerance, insulin resistance, and hyperandrogenemia in first degree relatives of women with polycystic ovary syndrome. J Clin Endocrinol Metab 88: 2031-2036.

54. Norman RJ, Masters S, Hague W, 1996 Hyperinsulinemia is common in family members of women with polycystic ovary syndrome. Fertil Steril 66: 942-947

55. Colilla S, Cox NJ, Ehrmann DA, 2001 Heritability of insulin secretion and insulin action in women with polycystic ovary syndrome and their first degree relatives. J Clin Endocrinol Metab 86: 2027-2031.

56. Legro RS, Bentley-Lewis R, Driscoll D, Wang SC, Dunaif A, 2002 Insulin resistance in the sisters of women with polycystic ovary syndrome: association with hyperandrogenemia rather than menstrual irregularity. J Clin Endocrinol Metab 87: 2128-2133.

57. Pierpoint T, McKeigue PM, Isaacs AJ, Wild SH, Jacobs HS, 1998 Mortality of women with polycystic ovary syndrome at long-term follow-up. J Clin Epidemiol 51: 581-586.

58. Kuczmarski RJ, Flegal KM, Campbell SM, Johnson CL, 1994 Increasing prevalence of overweight among US adults. The National Health and Nutrition Examination Surveys, 1960 to 1991. JAMA 272: 205-211.

59. Manson JE, Colditz GA, Stampfer MJ, et al, 1990 A prospective study of obesity and risk of coronary heart disease in women. N Engl J Med 322: 882-889.

60. Goldzieher JW, Green JA, 1962 The polycystic ovary. I. Clinical and histologic features. J Clin Endocrinol Metab 22: 325-338.

61. Kiddy DS, Sharp PS, White DM, et al, 1990 Differences in clinical and endocrine features between obese and non-obese subjects with polycystic ovary syndrome: an analysis of 263 consecutive cases. Clin Endocrinol 32: 213-220.

62. Balen AH, Conway GS, Kaltsas G, et al, 1995 Polycystic ovary syndrome: the spectrum of the disorder in 1741 patients. Hum Reprod 10: 2107-2111.

63. Norman RJ, Masters SC, Hague W, Beng C, Pannall P, Wang JX, 1995 Metabolic approaches to the subclassification of polycystic ovary syndrome. Fertil Steril 63: 329-335.

64. Taponen S, Martikainen H, Jarvelin MR, et al, 2003 Hormonal profile of women with self-reported symptoms of oligomenorrhea and/or hirsutism: Northern Finland birth cohort 1966 study. J Clin Endocrinol 
Metab 88: 141-147.

65. Talbott E, Guzick D, Clerici A, et al, 1995 Coronary Heart Disease Risk Factors in Women With Polycystic Ovary Syndrome Arterioscler Thromb Vasc Biol 15: 821-826.

66. Laitinen J, Taponen S, Martikainen H, et al, 2003 Body size from birth to adulthood as a predictor of self-reported polycystic ovary syndrome symptoms. Int J Obes Relat Metab Disord 27: 710-715.

67. Hamilton-Fairley D, Kiddy D, Watson H, Paterson C, Franks S, 1992 Association of moderate obesity with a poor pregnancy outcome in women with polycystic ovary syndrome treated with low dose gonadotrophin. Br J Obstet Gynaecol 99: 128-131.

68. White DM, Polson DW, Kiddy D, et al, 1996 Induction of ovulation with low-dose gonadotropins in polycystic ovary syndrome: an analysis of 109 pregnancies in 225 women. J Clin Endocrinol Metab 81: 3821-3824.

69. Kousta E, White DM, Franks S, 1997 Modern use of clomiphene citrate in induction of ovulation. Hum Reprod Update 3: 359-365.

70. Sagle M, Bishop K, Ridley N, et al, 1988 Recurrent early miscarriage and polycystic ovaries. BMJ 297: 1027-1028.

71. Wang JX, Davies MJ, Norman RJ, 2001 Polycystic ovarian syndrome and the risk of spontaneous abortion following assisted reproductive technology treatment. Hum Reprod 16: 2606-2609.

72. Norman RJ, Clark AM, 1998 Obesity and reproductive disorders: a review. Reprod Ferti 10: 55-63.

73. Kiddy DS, Hamilton-Fairley D, Bush A, et al, 1992 Improvement in endocrine and ovarian function during dietary treatment of obese women with polycystic ovary syndrome. Clin Endocrinol 36: 105-111.

74. Andersen P, Seljeflot I, Abdelnoor M, et al, 1995 Increased insulin sensitivity and fibrinolytic capacity after dietary intervention in obese women with polycystic ovary syndrome. Metabolism 44: 611-616.

75. Norman RJ, Davies MJ, Lord J, Moran LJ, 2002 The role of lifestyle modification in polycystic ovary syndrome. Trends Endocrinol Metab 13: 251-257.

76. Wilson PW, Abbott RD, Castelli WP, 1988 High density lipoprotein cholesterol and mortality. The Framingham Heart Study. Arteriosclerosis 8: 737-741.

77. Bass KM, Newschaffer CJ, Klag MJ, Bush TL, 1993 Plasma lipoprotein levels as predictors of cardiovascular death in women. Arch Intern Med 153: 2209-2216.

78. Legro RS, Kunselman AR, Dunaif A, 2001 Prevalence and predictors of dyslipidemia in women with polycystic ovary syndrome. Am J Med 111: 607-613.

79. Talbott E, Clerici A, Berga SL, et al, 1998 Adverse lipid and coronary heart disease risk profiles in young women with polycystic ovary syndrome: results of a case-control study. J Clin Epidemiol 51: 415-422.

80. Wild RA, Painter PC, Coulson PB, Carruth KB, Ranney GB, 1985 Lipoprotein lipid concentrations and cardiovascular risk in women with polycystic ovary syndrome. J Clin Endocrinol Metab 61: 946-951.

81. Pirwany IR, Fleming R, Greer IA, Packard CJ, Sattar N, 2001 Lipids and lipoprotein subfractions in women with PCOS: relationship to metabolic and endocrine parameters. Clin Endocrinol 54: 447-453.

82. Robinson S, Henderson AD, Gelding SV, et al, 1996 Dyslipidaemia is associated with insulin resistance in women with polycystic ovaries. Clin Endocrinol 44: 277284.

83. Vrbikova J, Cifkova R, Jirkovska A, et al, 2003 Cardiovascular risk factors in young Czech females with polycystic ovary syndrome. Hum Reprod 18: 980-984.

84. Austin MA, Breslow JL, Hennekens CH, Buring JE, Willett WC, Krauss RM, 1988 Low-density lipoprotein subclass patterns and risk of myocardial infarction. JAMA 260: 1917-1921.

85. Taponen S, Martikainen H, Jarvelin MR, et al, 2004 Northern Finland Birth Cohort 1966 Study. Metabolic cardiovascular disease risk factors in women with selfreported symptoms of oligomenorrhea and/or hirsutism: Northern Finland Birth Cohort 1966 Study. Clin Endocrinol Metab 89: 2114-2118.

86. Rose G, 1981 Strategy of prevention: lessons from cardiovascular disease. Br Med J 282: 1847-1851.

87. Verma S, Buchanan MR, Anderson TJ, 2003 Endothelial function testing as a biomarker of vascular disease. Circulation 108: 2054-2059.

88. Mather KJ, Verma S, Corenblum B, Anderson TJ, 2000 Normal endothelial function despite insulin resistance in healthy women with the polycystic ovary syndrome. J Clin Endocrinol Metab 85: 1851-1856

89. Paradisi G, Steinberg HO, Hempfling A, et al, 2001 Polycystic ovary syndrome is associated with endothelial dysfunction. Circulation 103: 1410-1415.

90. Orio F Jr, Palomba S, Cascella T, et al, 2004 Early impairment of endothelial structure and function in young normal-weight women with polycystic ovary syndrome. J Clin Endocrinol Metab 89: 4588-4593.

91. Tarkun I, Arslan BC, Canturk Z, Turemen E, Sahin T, Duman C, 2004 Endothelial dysfunction in young women with polycystic ovary syndrome: relationship with insulin resistance and low-grade chronic inflammation. J Clin Endocrinol Metab 89: 5592-5596.

92. Kelly CJ, Speirs A, Gould GW, Petrie JR, Lyall H, Connell JM, 2002 Altered vascular function in young women with polycystic ovary syndrome. J Clin Endocrinol Metab 87: 742-746.

93. Lerman A, Edwards BS, Hallett JW, Heublein DM, Sandberg SM, Burnett JC Jr, 1991 Circulating and tissue endothelin immunoreactivity in advanced atherosclerosis. N Engl J Med 325: 997-1001.

94. Ferri C, Pittoni V, Piccoli A, et al, 1995 Insulin stimulates endothelin-1 secretion from human endothelial cells and modulates its circulating levels in vivo. J Clin Endocrinol Metab 80: 829-835. 
95. Mather KJ, Mirzamohammadi B, Lteif A, Steinberg HO, Baron AD, 2002 Endothelin contributes to basal vascular tone and endothelial dysfunction in human obesity and type 2 diabetes. Diabetes 51: 3517-3523.

96. Diamanti-Kandarakis E, Spina G, Kouli C, Migdalis I, 2001 Increased endothelin-1 levels in women with polycystic ovary syndrome and the beneficial effect of metformin therapy. J Clin Endocrinol Metab 86: 46664673.

97. Kuller LH, Tracy RP, Shaten J, Meilahn EN, 1996 Relation of C-reactive protein and coronary heart disease in the MRFIT nested case-control study. Multiple Risk Factor Intervention Trial. Am J Epidemiol 144: 537-547.

98. Ridker PM, Hennekens CH, Buring JE, Rifai N, 2000 $\mathrm{C}$-reactive protein and other markers of inflammation in the prediction of cardiovascular disease in women. N Engl J Med 342: 836-843.

99. Freeman DJ, Norrie J, Caslake MJ, et al; West of Scotland Coronary Prevention Study, 2002 C-reactive protein is an independent predictor of risk for the development of diabetes in the West of Scotland Coronary Prevention Study. Diabetes 51: 1596-1600.

100. Festa A, D’Agostino R Jr, Howard G, Mykkanen L, Tracy RP, Haffner SM, 2000 Chronic subclinical inflammation as part of the insulin resistance syndrome: the Insulin Resistance Atherosclerosis Study (IRAS). Circulation 102: 42-47.

101.Redberg RF, Rifai N, Gee L, Ridker PM, 2000 Lack of association of C-reactive protein and coronary calcium by electron beam computed tomography in postmenopausal women: implications for coronary artery disease screening. J Am Coll Cardiol 36: 39-43.

102. Blackburn R, Giral P, Bruckert E, et al, 2001 Elevated $\mathrm{C}$-reactive protein constitutes an independent predictor of advanced carotid plaques in dyslipidemic subjects. Arterioscler Thromb Vasc Biol 21: 1962-1968.

103. Folsom AR, Pankow JS, Tracy RP, et al, Investigators of the NHBLI Family Heart Study, 2001 Association of C-reactive protein with markers of prevalent atherosclerotic disease. Am J Cardiol 88: 112-117.

104. Kelly CC, Lyall H, Petrie JR, Gould GW, Connell JM, Sattar N, 2001 Low grade chronic inflammation in women with polycystic ovarian syndrome. J Clin Endocrinol Metab 86: 2453-2455.

105. Guzick DS, Talbott EO, Sutton-Tyrrell K, Herzog HC, Kuller LH, Wolfson SK Jr, 1996 Carotid atherosclerosis in women with polycystic ovary syndrome: initial results from a case-control study. Am J Obstet Gynecol 174:1224-1229.

106. Talbott EO, Guzick DS, Sutton-Tyrrell K, et al, 2000 Evidence for association between polycystic ovary syndrome and premature carotid atherosclerosis in mid- dle-aged women. Arterioscler Thromb Vasc Biol 20: 2414-2421.

107. Vryonidou A, Papatheodorou A, Tavridou A, et al, 2005 Association of hyperandrogenemic and metabolic phenotype with carotid intima-media thickness in young women with polycystic ovary syndrome. J Clin Endocrinol Metab 1 [Epub ahead of print].

108. Christian RC, Dumesic DA, Behrenbeck T, Oberg AL, Sheedy PF $2^{\text {nd }}$, Fitzpatrick LA, 2003 Prevalence and predictors of coronary artery calcification in women with polycystic ovary syndrome. J Clin Endocrinol Metab 88: 2562-2568.

109. Birdsall MA, Farquhar CM, White HD, 1997 Association between polycystic ovaries and extent of coronary artery disease in women having cardiac catheterization. Ann Intern Med 126: 32-35.

110. Dahlgren E, Janson PO, Johansson S, Lapidus L, Oden A, 1992 Polycystic ovary syndrome and risk for myocardial infarction. Evaluated from a risk factor model based on a prospective population study of women. Acta Obstet Gynecol Scand 71: 599-604.

111. Franks S, 2001 Are women with polycystic ovary syndrome at increased risk of cardiovascular disease? Too early to be sure, but not too early to act! Am J Med 111: 665-666.

112. Speert H, 1949 Carcinoma of the endometrium in young women. Surg Gynaecol Obstet 88: 332-336.

113. Hardiman P, Pillay OC, Atiomo W, 2003 Polycystic ovary syndrome and endometrial carcinoma. Lancet 361: 1810-1812.

114. Dahlgren E, Friberg LG, Johansson S, et al, 1991 Endometrial carcinoma; ovarian dysfunction - a risk factor in young women. Eur J Obstet Gynecol Reprod Biol 41: 143-150.

115. Escobedo LG, Lee NC, Peterson HB, Wingo PA, 1991 Infertility-associated endometrial cancer risk may be limited to specific subgroups of infertile women. Obstet Gynecol 77: 124-128.

116. Coulam CB, Annegers JF, Kranz JS, 1983 Chronic anovulation syndrome and associated neoplasia. Obstet Gynecol 61: 403-407.

117. Furberg AS, Thune I, 2003 Metabolic abnormalities (hypertension, hyperglycemia and overweight), lifestyle (high energy intake and physical inactivity) and endometrial cancer risk in a Norwegian cohort. Int J Cancer 104: 669-676.

118. Weiderpass E, Persson I, Adami HO, Magnusson C, Lindgren A, Baron JA, 2000 Body size in different periods of life, diabetes mellitus, hypertension, and risk of postmenopausal endometrial cancer (Sweden). Cancer Causes Control 11: 185-192.

119. Balen A, 2001 Polycystic ovary syndrome and cancer. Hum Reprod Update 7: 522-525. 